\title{
Beyond Just Justice - Creating Space for a Future-Care Ethic
}

Ruth Makoff and Rupert Read, University of East Anglia

\begin{abstract}
Distributive justice relies on metaphors about spatial distribution. Modelling cross-temporal relations on cross-spatial relations in this way obscures how earlier groups become the later ones. Procedural justice metaphors rely on metaphors of (contemporaneous) contract and thereby on impartial reasoning. Their dominance is already problematic in the case of contemporary relations, but is even more so in the case of relations across time, where the conditions for later parties are controlled and created by earlier ones. Future generations should not be thought of as a distinct group living at a different temporal "location," but as who we will become. Thus, the frame of "justice" is much less appropriate for our relations to them than the frame of "care".
\end{abstract}

Acknowledgements

Thanks to an anonymous referee, to the editors, and to Ian Christie, Alice Crary, Mark Coeckelbergh, Tom Greaves, Phil Hutchinson, Anne J. Jacobson, Nigel Pleasants and (especially) Christopher Groves, for helpful comments on earlier drafts of this paper. 


\section{Introduction}

The human race faces an unprecedented ecological crisis. Philosophers are typically alive to this, but tend ${ }^{1}$ to think its challenges can be risen to by means of adapting traditional conceptual tools, especially by extending our notion of justice. This paper considers the limitations of the justice metaphor - for a metaphor is what it is - for adequately capturing the range of moral obligations that we have to future human beings (as well as to others in the present).

The justice metaphor has had widespread appeal for philosophers in thinking about future people in the first instance because it is the default way in which modern moral/political philosophers think ethically about all people. We regard the justice metaphor as a welcome improvement on ethically blind CBA-based [Cost-Benefit Analysis] approaches. And our concerns with relying on the justice metaphor to offer moral protection to future generations are not because of any scepticism as to their moral worth: quite the contrary! We shall argue that it is not in the final analysis meaningful or helpful to think of future people as merely our equals in the sense in which this is understood under "distributive justice" approaches. In Section II we outline why the various approaches to intergenerational justice (as outlined, for example, by Gosseries ${ }^{2}$ ) all problematically buy into a common set of justice metaphors. This set functions largely unquestioningly as the paradigm defining intergenerational moral obligations, in so far as they are held to exist at all. As we shall elucidate, most challenges to the notion of intergenerational justice

1. There are, of course, important exceptions. We discuss below (critically) utilitarian approaches to future-ethics. And, most notably: we ourselves build in what follows on the important and growing "care" tradition in ethics and political philosophy. See for instance Fiona Robinsons's "Global care ethics: beyond distribution, beyond justice" (Journal of Global Ethics 9:2 (2013: 131-143), a paper which, superficially, might sound highly similar to our own. And indeed we find Robinson's approach broadly conducive. To anticipate briefly the argument of our paper, some important differences are: (i) unlike us, she does not challenge the pre-eminence of "theoreticism"; she does not propose (as we do) a metaphor-based approach. And (ii) crucially, she does not consider the salience of time as a limit on the extent to which distributive justice is an appropriate frame. Someone in this tradition who does explicitly consider the salience of time is Michael Slote, who has been a key figure in the mainstream incorporation of feminist thinking about care in recent years. Again, we find Slote's general approach helpful. Unfortunately, his thinking about time is one of the weakest points in his work. Slote argues that we invariably have stronger obligations to those who are temporally immediate than to those who are temporally distant, and that an ethics of empathic caring can capture this point. We will argue, on the contrary, that always preferring the present to the future involves a failure to register the distinctiveness of our relationship with the future and of its call upon us. There are some circumstances in which we should privilege obligations to future people. (To get a sense of the difference between ourselves and Slote on this key point, see especially The ethics of care and empathy (London: Routledge, 2007: 27)).

2. Gosseries (2008). 
to date are made by those seeking to question the very basis for assigning moral worth to future generations. That is, those that defend the notion of intergenerational justice take themselves largely also - and simultaneously - to be defending the moral relevance of future generations at all. However, we aim to question the ambition of making "intergenerational justice" one's exclusive aim, and to propose instead a complementary and partly substitutive ${ }^{3}$ aim, one that is at least as important (and, in our view, actually much more apposite).

We think, in fact, that the only way ultimately of treating future people fully seriously is to not merely to treat them via a "justice"-based approach, which has its home in relations between present people, ${ }^{4}$ and in interactions across space rather than time. This is in so far as: (i) Distributive justice relies on metaphors about spatial distribution - we will argue that modelling cross-temporal relations directly on cross-spatial relations in this way is morally misleading and obscures how earlier groups become the later one(s); and (ii) Procedural justice metaphors rely on metaphors of (contemporaneous) contract and negotiation and thereby on impartial reasoning. We will argue here that their dominance is already limited and problematic in the case of contemporary relations, but that it is even more so in the case of relations across time, where the conditions for later parties are controlled and created by earlier ones. Rather, we argue in Section III, intergenerational moral relationships need to be conceived of by foregrounding developmental metaphors - the emergence of later generations from current and past generations - and moral reasoning modelled more strongly on conceptual metaphors of care. For, following Wittgenstein, ${ }^{5}$ we do not propose an alternative theory to replace justice metaphors nor advocate a monistic ethic for intergenerational relations. Rather, we advocate developing a (different) range of moral metaphors in different ethical cases to aid moral thinking, and focus here on highlighting the limitations in the justice metaphors that

3. I.e. "Intergenerational justice" can be useful, but should be less frequently used as the primary framing of intergenerational moral/political relationships.

4. Such that, unfortunately, the case of future generations is frequently presented as an outlier, a "special" case (whereas in our view, by contrast, it ought to be the central case). Here is an egregious, influential example of such a presentation: Brian Barry refers to "the rather strange case of future generations", by contrast with "more familiar cases". (This is from his "Intergenerational Justice in Energy Policy" in MacLean and Brown's Energy and the Future (Totowa, NJ: Rowman, 1983: 18).) As we shall explain, we see taking care of future generations as something like the first virtue of human institutions.

5. There is no further explicit reference to Wittgenstein in the present paper. But those who understand Wittgenstein's post-theoreticist philosophical sensibility will, we think, see his influence implicitly, over and over again, herein. In this sense, our paper has an affinity with what Rosalind Hursthouse says of her thoroughly Wittgensteinian book On Virtue Ethics (Oxford: OUP, 1999: 16), a work which similarly does not, except on that page, refer to Wittgenstein explicitly at all. 
have become overly dominant in the case of intergenerational moral relationships (but which we are not seeking to eliminate entirely), and on other metaphors that we think it helpful to allot a stronger role to in moral discourse. In the case of both (i) and (ii), our suggestion is that an ultimate commitment to caring about the beings in question is what underlies (and can be unfortunately effaced by, and should sometimes replace) the commitment to justice.

II. The limits of the justice paradigm for thinking about the future

\section{II. $i$ Best cases for the justice paradigm}

Let us think for a moment about how justice-talk works in the present. Take "Justice for janitors" : a good case for use of the distributive justice paradigm for thinking about the present, in that it seeks a fairer distribution of economic resources between janitors and other economic actors (as well as calling for better working conditions, etc.). However, it should be noted:

a) It remains the case that the reason we care about justice for janitors has its roots beyond justice. It has to do with caring about janitors: caring about fellow human beings.

b) Also: justice is a mitigatory ethic. One might almost say that it is a necessary evil, in a society that is deeply imperfect. But let us not "make a virtue out of a necessity" and fool ourselves into thinking that justice then becomes truly a "first virtue" in the Rawlsian sense!" It should not be represented as a genuinely utopian project in this regard. It seems like the best we can have because of how thoroughly economically liberal our society is. This is a point then about how justice is a virtue for a society that may be overcome: a point about the possible (limited) future of justice. ${ }^{8}$

These two points, (a) and (b), are linked by the virtue of care being, we claim, an underlying basis for our society that to some extent makes

6. See e.g. http://justiceforjanitors.ca/.

7. Rawls 1971, A Theory of Justice, Oxford: Oxford University Press. For a Wittgensteinian critique of Rawls's claim to have established that justice is the "first virtue" of political philosophy, see Rupert Read's "Wittgenstein vs. Rawls", published in V. Munz, K. Puhl and J. Wang (eds) Proceedings of the Kirchberg Wittgenstein Symposium 2009: Language and World (Frankfurt: Ontos, 2010).

8. Cf. in this context the useful work of Buchanan (Buchanan, Allen E., Marx and Justice, Rowman and Littlefield, 1982), who interprets Marx as arguing that tools of justice and rights only become necessary in a liberal capitalist society, to correct for the systemic manufacturing of conflict between individuals in such a society. 
justice irrelevant or at best secondary now, and that could do so to a greater extent in (and for) the future.

However, it is important to note that our concern with this limitation of distributive justice is not also a criticism of equality. The two are not synonymous, and whereas the normal view is that one might be in favour of distributive justice but not necessarily of equality (because fairness need not, allegedly, require equality of anything), our view is less common: we argue that one should be in favour of equality but not necessarily of distributive justice. ${ }^{9}$

Now let us turn to a good case (we can think of none better) for relatively unapologetic application of the distributive justice paradigm to our relations between generations: thinking about spreading the burden of pension-requirements fairly across generations. ${ }^{10}$ This is reasonable to take as a case of justice because thinking about interest rates can be used as a partial basis for determining how to distribute pools of money and burdens of payment. However, this case faces not only the two problems described in the previous paragraph but also the additional problem that calculations about the wealth of the next generation depend critically upon assumptions about economic "growth" - and that these assumptions are subject to the constraints we inevitably face in a world pressed up against the ecological limits to growth. ${ }^{11}$ When we start thinking ecologically, we can no longer think purely distributively. Moreover, pensions-policy, to boil it down to its simplest form, requires that children pay their parents' pensions. But this requires us to think adequately about the relationship of parents to children. Doing so will be the burden of the latter part of the present paper. And what we shall seek to show is that this relationship cannot be understood adequately as a relationship of justice (or injustice).

So: there are cases where a reasonably decent case can be made for talking meaningfully about distributive "intergenerational justice". But

9. See on this, for example, Read's (2011).

10. For example, as Willetts frames the debate, e.g.: Willetts, David M.P., "Baby boomers can't leave the younger generation to pick up the pensions bill", http://www.theguardian.com/society/joepublic/2010/feb/10/baby-boomer-pensions-ageing-population (Although this is not to suggest agreement with the policy that he advocates).

11. See, for example, Meadows et al. (2005); Rockström, J., W. Steffen, K. Noone, А. Persson, F. S. Chapin, III, E. Lambin, T. M. Lenton, M. Scheffer, C. Folke, H. Schellnhuber, B. Nykvist, C. A. De Wit, T. Hughes, S. van der Leeuw, H. Rodhe, S. Sörlin, P. K. Snyder, R. Costanza, U. Svedin, M. Falkenmark, L. Karlberg, R. W. Corell, V. J. Fabry, J. Hansen, B. Walker, D. Liverman, K. Richardson, P. Crutzen, and J. Foley, (2009) "Planetary boundaries: exploring the safe operating space for humanity". Ecology and Society 14(2): 32; and The Post-Growth Project (eds. Blewitt, John and Cunningham, Ray; London: London Publishing Partnership, 2014). 
even the best of these cases face a series of serious limitations with justice as the exclusive metaphor.

In the case of procedural justice it is more obvious how it works well in the present: as the formal ideal for the organisation of law courts. This is the paradigm from which all other cases of procedural justice initially spring, such as its importance for international negotiations. ${ }^{12}$ (Procedural justice might eventually start to wither away as the law itself did - but it requires a utopian ambition exceeding ours to take this possibility, gestured at in Marx, very seriously, because it requires imagining the end of criminality, or at least a very different way of dealing with and conceptualising criminality. ${ }^{13}$ )

However, when one seeks to extend procedural justice across time, it quickly breaks down into absurdity. Procedural justice is robust for welldefined institutional circumstances in the here and now, in such paradigm cases as the law courts - it is hopeless, we will argue in II.iii, as a way of seeking to include our descendants whose lives will not overlap with ours.

\section{II. ii Motivation for a new methodology}

It may seem to underplay the richness of the literature on intergenerational justice to seek, as we are doing, to draw attention to its significant limitations in the case of our obligations to future generations. For this literature hosts a wide range of different theories of intergenerational justice - for example, libertarian, communitarian, contractarian, reciprocitybased. ${ }^{14}$ Given that people are already aware of and responsive to key problems facing intergenerational applications (such as non-identity and non-reciprocity, discussed below) and seeking to accommodate them within justice theories, how, then, can we contend that one might want to start thinking about intergenerational moral relationships in terms other than justice? Surely we cannot be doing justice justice.

However, we are unconvinced by the very idea that moral and political philosophy should be in the business of devising theories. Rather, it should seek to discuss and draw from (often multiple) distinct moral meta-

12. See, for example, "Ethical Issue Eight" of the Tuana et al. (2006) White paper on the ethical dimensions of climate change. Pennsylvania State University, PA: Rock Ethics Institute. 13. Some useful indications of what this latter might involve are to be found in Jared Diamond's (2012) The world since yesterday: What can we learn from traditional societies? London: Penguin. Diamond in effect shows in this book how "justice" is a frame well-suited only for large, anonymous societies. In smaller scale situations, among people who have at least some kind of connection with each other, what matters is restoration of relations rather than a blind sense of right or wrong.

14. Gosseries, Axel and Meyer, Lukas H. (eds.) (2009). 
phors which may be more or less helpful. Metaphors which make maximal sense of the domain in question: which shed light on it more helpfully than others, and that lead our thinking (and action) in fruitful rather than harmful directions. One should do this in a way that preserves, moreover, one's understanding that these are metaphors, and thus preserve and enhance one's intellectual "autonomy," one's capacity as a thinker.

We are concerned then that justice-based approaches to moral and political reasoning have come to serve, for their proponents, as a justice "paradigm" that frames all moral discussion of intergenerational reasoning; a paradigm whereby advocates attach so strongly to several commonly held and centrally placed justice metaphors that they barely recognise that there might be other ways of thinking ethically about these relationships. Indeed, most criticism of the intergenerational justice framework comes from (weak ${ }^{15}$ ) environmental sceptics; from those, such as Beckerman and Pasek, who would question the very idea of the existence of strong moral obligations to future generations. This is allegedly because, firstly, their current non-existence means they cannot be assigned rights that would "trump" over those of present generations, ${ }^{16}$ and secondly, while they may still have moral standing, they are assumed to be richer than the current generations ${ }^{17}$ and their interests are thereby thought to be less worthy of attention than threats to the human rights of contemporaries. ${ }^{18}$ So for those defending strong intergenerational moral obligations against these kinds of arguments, such moral obligations have simply become synonymous with the notion of intergenerational justice. Tremmel, for example, describes the latter as "the ethics of the future" that defines the "new ethics of future responsibility". 19

But this is despite the ongoing struggle (as with much of moral philosophy) to find a theory that is in fact an adequate "match" for moral intuitions; in particular, to deal with the inadequacies of theories of justice intergenerationally. For instance, while Gosseries notes that "our philosophical theories on justice fall astonishingly short of expectations in attempting to deal with the normative issues raised by environmental and resource depletion problems, ${ }^{20}$ he nevertheless supposes that every time we come across new and relevant environmental concepts - such as

15. That is, they are not sceptical of the existence of serious environmental problems such as anthropogenic climate change.

16. Beckerman and Pasek (2001).

17. Beckerman and Pasek (2001: 105). As made clear in our invocation of Meadows et al. (2005), amongst others, we contest this rash assumption (unfortunately largely shared by Rawls) vigorously!

18. Beckerman and Pasek (2001: 123).

19. Tremmel (2009).

20. Gosseries (2008: 61). 
"sustainable development", "ecological debt," "ecological footprint" these must be "retranslated every time into the specific language of each theory of justice". This, for Gosseries, is a challenge, but is not, crucially, taken as a sign that some other ethical discourse might be needed as well or indeed even instead. While on paper he acknowledges the theoretical possibility that we might in principle require "a complete revision" of justice theories, in practice he always seems rather to suppose that the "existing language - in this case theories of justice - painstakingly constructed by successive generations of practitioners provide[s] sufficient vocabulary to deal with the issues in hand". ${ }^{21}$ In the rest of this paper, however, we present some reasons to think that our moral reasoning about future people (and indeed about relationships with non-humans and even our human contemporaries) is made plain-misleading by having to be wedded so strongly to this justice discourse, and obscures otherwise important features of these moral relationships. We describe, in II.iii and II.iv., the problems we find for intergenerational relationships with the central families of metaphors used by theories of distributive and procedural justice, respectively, and explain why the various families of theories of justice (as outlined primarily by Gosseries ${ }^{22}$ ) all problematically adhere to these metaphors.

\section{II. iii The Distributive Justice Metaphor(s)}

Let us offer some leading examples of the distributive justice metaphor, presented typically as the main alternative to CBA approaches in envi-

21. Gosseries (2008: 62). To put the matter for a moment in broadly Kuhnian terms: we say that the justice "paradigm" is in crisis, and is becoming "monstrous", as Copernicus said of the Ptolemaic system, in its efforts to get through this crisis. However, we think that to think that what one is doing is providing a theory - to think of one's enterprise as broadly scientific - is part of the problem, rather than of the solution. Better even than for justice advocates to think of themselves as having a paradigm in crisis that has grown monstrous, would be, in our way of seeing things, for them to come to see that they have never really had a paradigm at all, only the illusion of one, or at very best a fragment of one. Gosseries himself comes excruciatingly close to recognising this problem, and acknowledging at least the need for multiple perspectives within a broad justice framework. He argues, in his concluding observations on various theories of justice, that they "provide resources for thinking not just along different lines, but also for broaching the issue of intergenerational justice through the prism of various logics which...can generate a multiplicity of implications. This is particularly true once the ultra-simplified world represented here is enriched with a set of additional variables to bring it closer to the real world. Each of these theories can respond differently for example to demographic fluctuations." (p69). However, his quasi-scientistic language and refusal to depart from the language of theory means that he fails to provide the kind of basis for liberating ethical thinking more fully from its over-attachment to particular metaphors, and from recognising them as such.

22. Gosseries (2008). 
ronmental policy, in particular, in climate change literature. Take for instance the Center for Climate and Energy Solutions, which describes intergenerational equity as "The fairness of the distribution of the costs and benefits of a policy when costs and benefits are borne by different generations". ${ }^{23}$ Even more explicitly, Page understands intergenerational justice as part of the same "set of questions" for "global distributive justice" vis-à-vis climate change, that is, "how benefits and burdens should be distributed within and between generations". ${ }^{24}$ And Anand and Sen have proclaimed that our obligations to future generations are "a matter of distributional equity". ${ }^{25}$ Crucially, this conception of intergenerational equity or justice goes beyond a more general concern for intergenerational obligations; "the basic belief," which Anand and Sen also express, "that the interests of future generations should receive the same kind of attention that those in the present generation get". ${ }^{26}$ Rather, the concept asserts that such attention be interpreted distributionally. And distribution means, roughly, primordially: taking a bunch of stuff, and divvying it up.

Under this view, one's moral obligations to future generations should be determined by one's principle of justice. Page thus analyses our obligations to future generations according to one's views as to the "currency," "shape" and "scope" of justice ${ }^{27}$; that is what it is that should be distributed fairly, whether according to (e.g.) equality, priority or sufficiency, and which people count as relevant for such just distributions. Under this family of approaches, we fail to meet our obligations to future people and treat them unjustly when we fail to ensure that distributive patterns between generations meet the particular distributional principle advocated. ${ }^{28}$

Aspects of this influential approach seem reasonable and attractive. In particular, its grounding in the kind of appeal made by Anand and Sen to the "universalism" of the "shared claim" that all humans have "the basic capability to lead worthwhile lives" 29 highlights the needs of (and the meaningfulness of the lives of) those living in the future. Our use of "resources" 30 now can diminish their ecological conditions and abilities to meet their needs - can, in this sense, leave them less than we have.

23. http://www.c2es.org/science-impacts/basics/glossary.

24. Page (2007: 225), our emphasis.

25. Anand and Sen (2000), discussed in the context of sustainability.

26. Anand and Sen (2000: 2030).

27. Page (2006: 50-51).

28. Since the aim is to establish the just "profile of benefits and burdens that we should aim for in our dealings with contemporaries and future generations", Page (2006: 96).

29. Anand and Sen (2000: 2030).

30. We have scare-quoted this word because of broadly Heideggerian worries that talk of "resources" inclines one tacitly to figure the Earth as one gigantic mine (and refusetip). We recommend the interested reader to consult Heidegger's (1977). 
This approach can provide a helpful counter to the dominant economic and political practices of aggregation and discounting of the future costs of dangerous climate change against the current benefits of refraining from mitigation, by framing the relationship in terms of distributive fairness. But the extension of this metaphor - the thinking of intertemporal distributional justice as strictly analogous to interspatial distributional justice - is problematic when it becomes "attached to" 31 as the primary (and often exclusive) method of conceptualising intertemporal relations. ${ }^{32}$ It is attractive to extend thinking about distribution over space - because one has (allegedly) already got a theory of this - to thinking about distribution over time. It makes one's task as a philosopher of the future (deceptively) easy. It is exactly this attraction that has to be exposed to view, and turned into the difficulty that it actually hides.

The intergenerational scenario is distinct from contemporary relations in a very particular way that is relevant here; time is uni-directional and manifests crucial asymmetries between generations: the very existence of one party depends entirely on the actions of the other. Aspects of this feature have been depicted in Parfit's problem of "non-identity", 33 which is often presented, as with many other features of intergenerational relationships, as a "challenge" that theories of justice need to be able to accommodate. ${ }^{34}$ Parfit draws attention to the fact that the very existence of future people is contingent on current policy decisions; different people are likely to be born as a result of different decisions. But, he asks, how can future people then be said to be harmed (e.g. through failing to implement an environmentally protective policy) if those particular individuals who would exist are different to those who would have existed under a different policy choice? For, Parfit suggests, harming a person is normally understood as making things worse for that person. We cannot have made things worse for future people if they would otherwise not have existed - different individuals would have lived and experienced the better set of conditions created by the alternative policy.

31. When we speak of "attaching" to ideas or metaphors, we have in mind the Buddhist understanding of this term. In this sense, we are suggesting that philosophers, especially political philosophers, need to practice "non-attachment" to their preferred vocabularies, on pain of otherwise being imprisoned by them.

32. Even if, as has become philosophical etiquette, justice-theorists acknowledge in principle that justice does not exhaust our moral obligations, very little is ever made of what else these might in fact constitute. This is most evident amongst political liberals such as Rawls (1993), Barry (1995) and Nussbaum (2006), who define a political conception of justice which is shared by and which ranges over various comprehensive conceptions of morality. But it was also present in Rawls prior to his development of "political liberalism". See also Beckerman and Pasek (2001: 14), and Page (2007: 3).

33. Parfit (1984).

34. Gosseries and Meyer (2009: 3). 
These are "different people choices". ${ }^{35}$ And if no person has been made worse off by the policy, how can it be said to be harmful? $?^{36}$

However, we have concerns with the very framing of the problem, for it stems from the way in which we deal with harms intragenerationally, and attempts to apply this to a very different kind of context intergenerational morality. That is, it only becomes a problem in trying to fit intergenerational relationships to the mould created by contemporary relations (here, notions of harm). Parfit and others do of course recognise that key features of intergenerational moral relationships are very different from those among contemporaries: the very purpose of the nonidentity problem is to look for the "moral reason" 37 which explains our intuitions if it cannot simply be that particular peoples' lives are made worse in "different people choices". But in seeking to offer such further explanations and search for "theory X" which tell us "which set of principles... we ought to accept" 38 as justifying our intuitions, theorists are attempting to apply the rules from one kind of case to another, which may not constitute a helpful or appropriate model. Indeed, we submit that in certain important respects intergenerational relationships are not analogous to intragenerational ones; we create future generations and their conditions, and should not think of them as in any way "already existing" at another temporal "location". 39 This structure, and our intuitions about how to deal with it, should rather be seen as constituting a different kind of case $^{40}$ that requires insight from other, additional metaphors, and which cannot be explained in terms of more fundamental principles, or a wholesale theory to "explain" them. Non-identity only seems to pose a problem when we try to import inappropriate modes of ethical thinking.

What we are suggesting here is that non-identity should not be regarded as a problematic issue for moral thinking about intergenerational relationships (construed as just a special case of our ordinary interactions). Rather, it should be foregrounded as part of an alternative,

35. Parfit (1984: 356).

36. NB Parfit's point here is not to suggest that it is not wrong to impact future people in this way. Rather his point is to ask how it is possible to understand this as wrong, and what "theory" we should adopt that will support our intuitions that harm has been done, if particular individuals cannot be said to have been harmed according to a comparative view of harm.

37. Parfit (1984: 363).

38. Parfit (1984: 361).

39. On the wider disanalogy between time and space, see Read (2003), "Against 'Time-Slices'." Philosophical Investigations 26, no. 1 (January 1, 2003: See p33 and p24, footnote 1).

40. This is not to say that we need to create a whole new set of claims and intuitions... they exist already in the way in which we think about future generations in other contexts - as, e.g., our children, as we outline in Section III. 
complementary and, we would advise, more dominant set of metaphors. The central moral question becomes, not "who is harmed by our actions?" but, "what kinds of future lives and circumstances should we facilitate in coming to be?". Or, again: "what kinds of future are we leaving to the beings, whoever precisely they will turn out to be, who will constitute our posterity?"

We now consider the failure of the distributive justice metaphor, as depicted in various theories of justice (manifested through particular distributive principles regarding the "currency" and "shape" of distributive justice $^{41}$ ), to make focal what is the focal feature of intergenerational relationships that underlies the problem of non-identity: the uni-directionality of time, and the creation of (conditions for) future generations by previous ones. While we will suggest that some theories (e.g. some versions of sufficientarianism) seem to struggle less than others in this regard, this is because they have already started to borrow tacitly from what we will tentatively call a model of developmental health, a metaphor that should be made primary and explicit.

Let us start with broadly egalitarian approaches, whereby the distributive justice metaphor can seem to imply that what is morally required is a broad equality in distribution (of goods, or well-being) between generations. This seems to represent a relatively progressive position in the case of contemporary relations. But in an intergenerational context, it risks inviting concerns that in "saving" for a future generation, a previous generation could leave them too much. Indeed, Solow has worryingly put forward just such a suggestion, which it is worth reproducing in full: ${ }^{42}$

You could make a good case that our ancestors, who were considerably poorer than we are, whose standard of living was considerably less than our own, were probably excessively generous in providing for us. They cut down a lot of trees, but they saved a lot and they built a lot of railroad rights-of-way. Both privately and publicly they probably did better by us than a sort of fair-minded judge in thinking about the equity (whether they got their share and we got our share or whether we profited at their expense) would have required. It would have been okay for them to save a little less, to enjoy a little more and give us a little less of a start than our generation has had.

This is both conceptually and morally problematic. We will return to further concerns about adopting the perspective of a "fair-minded judge" in Section II.iv. But for now note that the distributive metaphor here is conceptually misleading; by definition, the process of learning and the

41. Page (2006: 50-51).

42. Cited (uncritically) in Anand and Sen (2000: 2035). 
development of knowledge and technology means that any resulting improvements to the standard of living of future generations could not be meaningfully distributed more fairly between generations. In terms of the improvements brought by such development, ${ }^{43}$ future people will necessarily have "more" or "better" in some senses than previous generations - this is simply the notion of development (and of learning). Solow, as a development economist, is clearly aware of this. ${ }^{44}$ But its implications are overlooked in nonetheless considering this development distributionally, as though between two discrete societies, already existing in different temporal (as opposed to spatial) "locations", rather than as a process whereby one emerges from the other. For it is a necessary feature of development that future generations of any functioning society will "profit" at the "expense" (sic.) of previous generations.

There is also something morally abhorrent about the idea that we should withhold improvements to human society simply because more of the benefits are experienced by future people. We surely want if possible to improve our societies for the better, to leave future generations - our descendants - a better world than the one we inhabit, to improve their chances of surviving, flourishing and living fulfilling and secure lives. Indeed, some would say - and we would tend to agree - that this is the central purpose of many people's lives (especially obviously, perhaps, for parents)! However, as Anand and Sen suggest, the "universalism" in an intergenerational distributive equity perspective implies "an obligation to preserve the present-day economic opportunities (such as productive capacity) for the future, not necessarily to increase them". ${ }^{4}$

Rawls, on the other hand, does seem to conceive of his own, notionally egalitarian ${ }^{46}$ notion of "just savings" in the context of building and improving ones society or civilisation, and criticises those who have lamented the "chronological unfairness" of this directionality. ${ }^{47}$ This, then, is an improvement. Rawls claims that the "just savings principle can be regarded as an understanding between generations to carry their fair share of the burden of realizing and preserving a just society... during the whole course of a society's history". ${ }^{48}$ But it is difficult to see

43. This is not to suggest that all development does bring improvements, or, where it does, that it always brings uniform improvements to subsequent generations. Far from it! (We are in this connection, often sympathetic to critics of developmentality such as Deb, Lohmann, and Norberg-Hodge.).

44. Indeed, he offers a similar criticism of applying a maximin principle to intergenerational relationships: see Solow (1974: 33).

45. Anand and Sen (2000: 2035).

46. Just Savings is ordinarily considered as a form of intergenerational "Rawlsian Egalitarianism" (sic.) (Gosseries (2008: 68).

47. Rawls (1971: 291).

48. Rawls (1971: 289). 
why this idea should be understood in terms of distributive justice as Rawls wants - how, if later generations are properly to enjoy a better life than previous ones, it makes sense to talk of the intergenerational "understanding" in terms of a just distribution between generations at all. That is, Rawls is still overly caught up within an attachment to distributionalist frames and metaphors.

The distributionalist framing may seem plausible from Rawls's description of the generational burden (the savings left by one generation for the next), as a "fair equivalent in real capital... in return for what is received from previous generations". ${ }^{49}$ But what he means by a "fair equivalent" is not an economically equivalent quantity (which would, in any case seem odd to require of each generation, with different circumstances and different challenges). It is, in fact, "what is reasonable for members of adjacent generations to expect of one another at each level of advance... balancing how much at each stage they would be willing to save for their immediate descendants against what they would feel entitled to claim of their immediate predecessors", ${ }^{50}$ That is, there is a different "rate... for all stages". This continues until the "last stage at which saving is required", after which sufficient wealth has been accumulated to bring about "the full realization of just institutions and the fair value of liberty".

But this way of understanding intergenerational relations is worrying. One would need to significantly stretch this metaphor to apply it to dangerous climate change, or other environmental crises. For Rawls imagines society like a savings account - where a regular investment over time (in socio-economic infrastructure) can provide regular interest repayments (i.e. the wealth generated from this size of economy) which increase in size until it has accumulated enough for society to live justly and sufficiently from the interest. ${ }^{51}$ But, even if we (generously) assume that the savings need not represent accumulation, but a curb on each generation's use rate of natural resources and pollution sinks, it is not clear why the process of defining different appropriate savings rates at each stage is best understood as one of "just savings", or fairness. Such a characterisation is worrying, especially when Rawls says (foreshadowing Solow, cited above) that just savings "places an upper bound on how

49. Rawls (1971: 288), where "capital" is "knowledge and culture... techniques and skills" as well as "factories and machines". This is on balance a sadly-outmoded "productivist" vision of "capital", ill-suited for a post-growthist age.

50. Rawls (1971: 289).

51. Although, in terms of the economy's size, this latter point is preferable to assuming a need for continuous economic accumulation, which Rawls correctly counters in this section, arguing that "great wealth is not required" for a "just and good society". Rawls (1971: 190). 
much a generation can be asked to save for the welfare of later generations... Each age is to do its fair share... but beyond this more cannot be required". ${ }^{52}$

For example, if the concern of intergenerational equity or justice for future generations is to ensure equivalent burdens are placed on each generation, then the scenarios posed by dangerous climate change will create morally dubious outcomes. On the one hand, since burdens to future generations from dangerous climate change will be significantly heavier than those to current generations if we do not adequately mitigate emissions, an egalitarian intergenerational distributive justice approach might require reasonably radical mitigation targets so long as equivalent intergenerational burdens or levels of well-being were likely. However, on the other hand, the current and emerging generation, in committing to any such "burdens" or drop in standard of living, could be arguably treated inequitably vis-à-vis the previous generation, which (at least in industrialised countries) benefited from high emitting development but which increased the burdens from dangerous climate change and the concomitant requirement for significant cuts if further temperature rises are to be avoided. To treat our generation "fairly" (in terms of a "fair equivalent") might then seem to imply less radical climatechange-mitigation targets.

Furthermore, the prospect of radical mitigation targets might seem unfair if the current generation is considered in comparison to further future generations. For, if extremely strong mitigation efforts were successful in averting a $2{ }^{\circ} \mathrm{C}$ global mean temperature rise, ${ }^{53}$ once low/zeroemissions infrastructure is in place, further future generations could conceivably end up substantially better off in many respects and facing fewer burdens than the current generation. This could be deemed unfair from the perspective of intergenerational justice but would surely be morally preferable to a more nominally "just" outcome, where the current generation only marginally diminishes its average ${ }^{54}$ standard of living, but future generations increasingly suffer the impacts of increased temperature rises.

Rawls's advocacy of an intergenerationally distributive principle of each generation's leaving a "fair equivalent" is similar to reciprocitybased theories of distributive justice. As is well-noted in literature on intergenerational justice, theories based on reciprocity themselves face the additional "problem" that intergenerational relationships are typically

52. Rawls (1971: 298).

53. The temperature rise considered in international climate agreements to be dangerous (although we would follow others in arguing that this threshold should be set at $1.5^{\circ} \mathrm{C}$ or indeed lower).

54. We use "average" standard of living because of intragenerational inequities, which may and should be reduced. 
characterised by non-overlapping generations, and therefore by non-reciprocity.

Page has highlighted, for example, that "The vast majority of future individuals that will benefit from the modest amount of climate change avoided will never be in a position to repay the present generation for their sacrifice" 55 since the latter will no longer be living. Page calls this the "non-reciprocity problem", 56 and emphasises instead the model of indirect reciprocity, ${ }^{57}$ whereby we reciprocate for the benefits we receive by passing these on to future generations. We return in the next section to the significant problems with the procedural contractual metaphors that typically underpin reciprocity theories, the challenge of "non-overlapping generations". ${ }^{58}$ But to deal with, for now, the distributional principles implied by such a theory: indirect reciprocity means that we have no such intergenerational duties if we have not received certain benefits. Page is explicit, for example, in stipulating that "there can be no duty of fair reciprocity to pass on what one has not received". ${ }^{99}$ But to justify the "sacrifices" of current generations in taking mitigative action against climate change, he is then forced to assume that "members of the present generation have been bequeathed an atmospheric system largely devoid of dangerous impacts", that is, because such mitigative action could only be justified under indirect reciprocity if it involves passing forward benefits that we have received ourselves. ${ }^{60}$ However, it is not any longer clear that we have received such benefits. While rising concentrations will significantly worsen the harms from dangerous climate change in future, the changes to the climate system (e.g. in terms of increased incidence of severe storms) that we have already inherited are such that Page's assumption of a healthy climate system can, to put it mildly, no longer be made with confidence. This perspective could worryingly undermine the case for mitigative action, and makes our obligations to future generations oddly dependent on having already received equivalent environmental benefits from previous generations.

This echoes Gosseries's analogous concern with reciprocity as a theory of even contemporary justice: that, in "the case of a person with multiple congenital disabilities," if it turns out that she gives us "less in return for what society gave to her," this will undermine any further obligations to care for her (or for any other similarly dependent person) that we might

\footnotetext{
55. Page (2007: 231).

56. Ibid.

57. Originally proposed by Brian Barry (1991), referenced by Gosseries (2008: 63).

58. Gosseries and Meyer (2009: 3).

59. (2007: 237).

60. Ibid.
} 
otherwise feel. ${ }^{61}$ But, we would also note that the set-up in the first place of Gosseries's (counter-)example under the distributive justice metaphor reads profoundly uncomfortably; the very idea that we could make full sense of someone's "giving" less or more as an aggregative sum of their societal contribution, including not only economic productivity, but love, social bonds, community... is to misunderstand the meaning and value of these contributions as precisely not quantifiable, nor commensurable with other forms of "capital" (sic.). These are not the sorts of things that it makes sense to think about distributively.

Similarly, we would argue, applying metaphors of distribution to intergenerational relationships is a misleading way to consider and define obligations to future generations when it comes to environmental change, when what is at stake is the health, development and resilience of our ecosystems; our ecological pre-conditions, rather than simply a stockpile of a resource being distributed. This is true equally of theories of justice that turn instead on intergenerational applications of the Lockean Proviso - to leave "enough and as good" 62 for others. (Such a distributional framing contains a presumption that we need primarily to compare intertemporal stockpiles of "stuff", and (at best) maintain these, rather than to develop or nurture living systems or entities.)

This is "sufficientarianism". ${ }^{63}$ Such approaches are to some extent preferable to other intergenerational distributive principles. As Meyer and Roser argue, strong sufficientarianism is able to better accommodate many of the particular features that characterise intergenerational relations, such as uncertainty about the future and non-overlapping generations. ${ }^{64}$ In particular, it can deal with "non-identity," since, rather than relying on an understanding of harm as a worsened state of affairs for some particular individuals(s) (which, as discussed earlier, can mean that future people cannot be considered as harmed by environmentally destructive actions if those actions also bring into existence different people than would otherwise have existed), sufficientarianism specifies a threshold conception of harm, by which we can harm and fail to be just to future people if our actions cause them to "fall below the specified standard" of well-being. ${ }^{65}$

However, this position is by no means identical to what might be termed "enoughism". Our view is that the concept of "enough" should be

61. Gosseries (2008: 64).

62. Locke, The Second Treatise, Chapter 5, paragraph 27, in Laslett (1960).

63. Gosseries (2008: 69).

64. Meyer, Lukas H., and Roser, Dominic, "Enough for the Future", Gosseries and Meyer (2009: 243).

65. Meyer and Roser (2009: 229). 
central to political thought, non-negotiably so in an age of limits to growth. ${ }^{66}$ Contrary to the central assumptions of neo-classical economics, humans should not be conceived as having unlimited wants and desires, but as being capable of satiety and fulfilment. ${ }^{67}$ We think, as will become clear momentarily, that sufficientarianism risks taking insufficiently seriously what for us is central: the open-ended commitment we have or ought to have to making things genuinely better for our descendants. But we also think that sufficientarianism tends not to take seriously enough its own alleged emphasis on enough being enough where current generations are the recipients of justice: insofar as it allows endless material/consumerist expansion beyond the point of sufficiency. According to such a view then, sufficiency defines a threshold for what is owed to people as a matter of justice, but not a limit on what they are at liberty to appropriate. While "enoughism" would centre on a threshold which does not need to be exceeded, sufficientarianism tends to be the opposite - a threshold which can be exceeded as much as anyone wants.

Moreover, as we discuss in Section II.iv, sufficientarianism still implies a very much more limited set of obligations towards future generations. For example, as Gosseries points out of Brundtland's sufficientarianism, "once everyone's needs are covered, fairness does not require any further redistribution". ${ }^{68}$ And their appeal in dealing with non-identity draws its strength, we would argue, from starting to recognise aspects of the kind of developmental metaphor we have been advocating, that is, the unidirectionality of time. ${ }^{69}$ But, by failing to acknowledge the metaphor and by continuing to shoehorn such characteristics into the language of distribution, they create a misleading picture and, we will suggest, a serious risk of us not doing enough for future generations.

Let us illustrate the points of these last few paragraphs by indulging in an analogy. We plant a rosemary bush. There are a few small sprigs, say five, in the first year, and we know the bush will grow many more next year. How many should we take now? If we try to think in terms of an even distribution over time, we will encounter problems. Left as

66. See Meadows et al. (2005: 11 and Chapter 7, especially 238-240) and Scott Cato (1999: 42-44).

67. Daly and Cobb (1990: 85).

68. Gosseries (2008: 69).

69. This unidirectionality yields something else of importance hereabouts: a way in which one can generate a (ceteris paribus) reason for thinking that we ought to expect to be able to make things better for the next generation, even once we have jettisoned dangerous myths of "progress". The reason is this: one should expect that, other things being equal, human knowledge and wisdom will gradually improve, simply by virtue of us being historical beings, who can learn; including learning from our mistakes. (This argument is made in greater detail in Read's "Wittgenstein and the illusion of "progress": On real politics and real philosophy in a world of technocracy", forthcoming in Philosophy.) 
is, and tended to, the bush may have, say, four times as many sprigs next year and we will be able to harvest more. But if we try and achieve a broadly equal distribution of harvest across time by taking five now, and five next year, our plant will probably die. We could take three or four sprigs, and then try to take the same amount next year, but our plant probably will not be very healthy, may still die, and there are likely to be far fewer than twenty sprigs next year. What we need to do is take an amount that will not impede the growth and integrity of the plant - that is, maybe one sprig. Then next year we can take at least five times the amount (i.e. five sprigs) without impeding its growth or health. Of course we could, then, try to frame this distribution in sufficientarian terms - that we should limit the number of sprigs that we pick now to the number that will allow future harvests to be sufficient, because the plant's health has not been impeded. But then why is it helpful any longer to think primarily in terms of distribution? The underlying concern here is the changing health of the plant; its growth and development. And the danger is that if we attach too strongly to the distributional concern under even the sufficientarian approach, our attention is overly drawn to attaining particular limited outcomes; to doing just enough to achieve these, and deriving the maximum benefits we can here and now within these limits, when this may in fact mean that the health of the plant itself is always precarious, rather than flourishing.

Clearly, in this case it is we that benefit both now and in the future; one might object that we are simply acting in our longer term selfinterest, dis-analogously to the case of future generations. But the point of this particular analogy is not motivational (for those considerations see our discussion in II.iv, below); rather it is to highlight the limits in and to understanding the process of development over time predominantly distributionally. And the risks in focusing exclusively on this way of thinking are particularly cause for deep concern when the analogy is scaled up to consider our obligations to future generations with regard to the ecological conditions in which they will emerge. Given especially the facts of ecosystemic complexity and conditions of uncertainty, we therefore suggest that we need to give more primacy to moral metaphors that capture the underlying developmental dynamic, and focus instead on marrying the behaviours of present generations to the evolving health of the ecological systems that we (and future generations will) depend on.

The limits of the distributive metaphor for intergenerational moral relations, as expressed in various theories of justice, is, however, compounded by the adherence of such theories to a further, procedural, set of metaphors which we briefly outlined in II.ii. We turn to this now. 


\section{II. iv The Procedural Justice Metaphor(s)}

What underpins particular principles of distributional justice is often a further claim that the principles must be derived from procedurally just circumstances, methods or institutions. ${ }^{70}$ Anand and Sen, for example, follow their contention (cited above) that future people's needs must be met via intergenerational distributional justice by suggesting that this must constitute "sharing the capacity for well-being between present people and future people in an acceptable way... which neither the present generation nor. . future generations can readily reject". ${ }^{71}$ Such theories rely on procedural justice metaphors of contract and negotiation as neutral procedures that provide conditions of impartiality for determining and justifying principles of distribution (i.e. those in the contract traditions).

This group of theories, as Gardiner has discussed in detail, ${ }^{72}$ is subject in particular to what Page called the "problem of non-reciprocity", which we noted earlier stems from the existence of non-overlapping generations. The theories most familiarly susceptible to this problem are those based on "mutual advantage"; the idea that "a "rational" agent i.e. one acting exclusively out of self-interest - will serve his best interest by engaging in a co-operative venture and submitting to certain social rules accordingly". ${ }^{73}$ Mutual advantage follows directly in the Hobbesian social contract tradition in requiring that rules must be in the best interests of all who co-operate, and that this is what provides the reason for them to do so. ${ }^{74}$ This is a problem in the intergenerational sphere because justice conceived as a mutually beneficial arrangement cannot be applied. ${ }^{75}$ For, as Gardiner has argued in the case of dangerous climate

70. One notable exception here is Nussbaum, who explicitly eschews contractarian, procedural approaches, and for that reason we find her account of justice a significant improvement on others, and are extremely sympathetic to her capabilities approach. However, her understanding of justice is problematic in continuing to be wedded to the neutralist framework of political liberalism. Further, her account of what is owed to recipients of justice is conceived in terms of "objective" entitlements to key capabilities, precisely as opposed to "compassion and humanity" (Nussbaum 2006: 336-337).

71. Anand and Sen (2000: 2038).

72. Gardiner, Stephen, "A Contract on Future Generations?", Gosseries and Meyer (2009).

73. Gosseries (2008: 64).

74. Barry (1995: 31); Gardiner (2009: 79).

75. Rights-based accounts share aspects of the procedural justice metaphor in this respect. As Jonas (1985: 38-39) has highlighted, "the traditional idea of rights and duties" is "grounded upon reciprocity, according to which my duty is the counterpart of another's right, which in turn is seen as the like of my own right...". "This scheme fails" in the case of future generations since the "nonexistent" do not yet have rights (until they exist) and cannot have reciprocal duties to us; the rights/duties scheme therefore needs to be significantly revised so as to preclude the possibility of asking the question, "What has the future ever done for me? Does it respect my rights?". 
change, "control of the situation rests completely within the current generation". ${ }^{76}$ In this case, since the current generation has already inherited an overpolluted planet, it is not in its (narrowly conceived, at least) selfinterest to "co-operate" with future generations - it "will achieve nothing for itself by holding back". ${ }^{77}$ As has been well noted, there is no guarantee that the rules will be respected and that some generations will not free ride, since non-contemporary generations cannot provide enforcement. ${ }^{78}$ Proponents of the theory are forced to tenuously assume that mutuality and/or enforcement can be provided via the overlapping of generations.

Similar problems occur, as Gardiner has noted, for theories based on reciprocity, and contract theorists such as Rawls. Page argues that the problem for reciprocity-based theories can be largely circumvented by some version of an "international stewardship" 80 modification, at least in the case of public goods such as having a "hospitable climate system". ${ }^{81}$ This means, as we noted in the previous section, that we "reciprocate" to the previous generations for benefits they left us not directly to them, but "indirectly" by passing on benefits to future generations, ${ }^{82}$ so that reciprocity is understood in terms of "fairness" rather than mutual "selfinterest" ${ }^{83}$ But this move to "indirect reciprocity" glosses over the fundamentally asymmetrical and non-reciprocal relationship between generations, since it is not then clear that indirect reciprocity should still count as reciprocity at all. The move here (as with the assumption above of mutuality/enforcement via overlapping generations) is artificial; it treats this rather central feature of intertemporal relationships as a challenge ${ }^{84}$ for existing theories of contemporary moral relations to overcome and adapt to, rather than, as we are doing, foregrounding it as a central feature of intergenerational relationships which appropriate moral metaphors should be defined by. This is, we suggest, a classic example of how a

76. Apart from, that is, where generations overlap, when Gardiner supposes that there is some degree of reciprocity in preserving the advantage of social cooperation. See Gardiner (2004: 30).

77. Gardiner (2004: 30).

78. Gosseries (2008: 64-65); Gardiner (2009) and Barry (1995: 33) also raise similar concerns with free-riding even among contemporaries where people are assumed to be either self-interested or in single-minded pursuit of their own ends (p37).

79. See Gardiner (2009: 99-108) for a discussion of some significant inadequacies. The inadequacies are stark when it comes to serious lengths of time. Consider, for example, the asymmetry of benefits and costs in relation to a nuclear power station: this produces energy for 30 years and leaves waste for 300000 years.

80. Page (2007: 232-238).

81. Page (2007: 234).

82. Page (2007: 232-233).

83. Page (2007: 227).

84. This is in fact how Gosseries and Meyer (2009: 3) have explicitly described it. 
frame/paradigm (here, that of reciprocity) constrains and deforms one's thinking, to the point of absurdity. By contrast, we might reasonably expect that "indirect reciprocity", to represent any form of reciprocation at all, should mean something like: I reciprocate something good that you have done for me by doing something good for your sister, who then does something good for you. A larger scale example that might plausibly still count as indirect reciprocity might be Local Exchange Trading Schemes (LETS), ${ }^{85}$ in which members provide goods and services (e.g. plumbing, gardening, tutoring...) to one another "for free", in the knowledge that they can receive "free" services from other members as and when they need, within reason. But by the time one moves past such a closed system to movements such as Pay It Forward, ${ }^{86}$ where individuals are encouraged to "repay" good deeds done to them by similarly helping others, it is unclear that this is indirect reciprocity any longer. Such a movement is supposedly constructed in the language of reciprocity, but since (unlike in the previous cases) one does not expect to receive anything further back, it is motivated primarily by being inspired from care shown to oneself to go on to care for and to help others. In other words, it is transitional away from contract-based metaphors grounded in mutual self-interest and towards perspectives based on altruism, care and empathy.

The problems stem from theoretical over-attachment to these central metaphors of justice themselves. Within the contract tradition, what is fair is based on what is decided in a neutrally structured negotiation, or in something like a court. In the course of the negotiation or the court proceedings, one deploys principles to make one's case. These principles, ideally, secure a reasonable agreement (some would argue, a "rational" agreement). This is the basis for most "social contract" thinking, and quite explicitly, of course, for Rawls's pseudo-jurisprudential "pure procedural justice". And, as Foster remarks: "[There is no fairness], there are no genuinely equitable relations, except within the present". ${ }^{87}$ Contractarianism or contractualism, such as Rawlsian "ideal theory", takes as its standard case such relations within the present.

The true depth of the problem is almost recognised by Gardiner, who argues that this kind of problem creates an "Idealization Dilemma" for contract theories. ${ }^{88}$ If, he argues, as in contractarianism, "the basic claims about cooperation are supposed to be matters of descriptive fact" then "if it were to turn out that the basic claims fail to carry over to

85. See http://www.letslinkuk.net/.

86. See http://www.pif.org.uk/.

87. Cf. e.g. p.116 of John Foster's (2008).

88. Gardiner (2009: 93). 
the intergenerational setting... then it seems that one would be forced to conclude that the contractarian model fails to apply". We would then need to reject the particular contract model, or even conclude "that some other kind of moral theory altogether must be invoked". However, he suggests that "on a paradigm contractualist theory, the basic claims about co-operation need not describe matters of fact, but rather merely report how the situation arising between various parties ought to be conceived." ${ }^{89}$ But further, he argues, even contractarians can adopt this kind of contractualist "idealization strategy", in that "the alleged 'descriptive facts' against which contractarians judge their theories are not the facts of the world that we live in, but the hypothetical world of the state of nature.". 90 Yet, as Gardiner then points out, this response alone is insufficient; contract theorists must also show that it is "both possible and appropriate to conceive of that [intergenerational issue] in those terms... For some descriptive facts about the world are sufficiently deep that they play a role in defining the problem at hand: that is, they are essential to the normative definition of the problem as the kind of problem it is".

This is precisely our concern. And our contention has been that, while one can attempt to twist contract metaphors so as to show them as "possible and appropriate" for framing intergenerational moral relationships, the "paradigm" has become monstrous, in a case like this. It requires desperately trying to force things into a certain mould, and the effort to preserve its framing metaphors has ceased, by this point, to be of any help to clarity. Disappointingly, Gardiner pulls his punches and stops short of concluding anything of this kind, instead arguing that "If the pure intergenerational problem is really a particular kind of collective action problem, then there is reason to think that the contract theory approach can be resurrected", ${ }^{91}$ for example, by a "better theory of chain connection" (i.e. of why different generations should cooperate, so far only grounded via generational overlap). But this reluctance on Gardiner's part to go as far as he ought is unsurprising given that he operates within the tradition of moral theorising, and the notion of moral metaphor (as non-exclusive, such that we do not completely reject the contract metaphor as such, but argue that there are other, more helpful metaphors for our moral thinking here which more focally deserve our attention) is not available to him.

89. Ibid. We are suggesting that it ought to be conceived differently. That the kind of thinking to be found in George Lakoff's Moral politics (Chicago: U. Chicago, 2010) and in Wittgenstein's entire corpus suggest a different kind of starting point from contractualist theorising.

90. Gardiner (2009: 94).

91. Gardiner (2009: 116). 
So let us respond to a possible objection, which follows Gardiner's suggestion that contract theory need not describe real-world facts but an idealised conception of how we ought to think of things intergenerationally. Our concerns, above, along with Foster, that there are "no genuinely equitable relations, except within the present" might be thought questionable in that it is arguably precisely when unequal power imbalances exist that we require impartial reasoning from imagined scenarios which structurally model true conditions of fairness (as in, for example, Rawls's hypothetical original position); to show what fair outcomes that represent the interests of all would be. This would equally, it might further be argued, be the case in scenarios amongst contemporaries where there exist power imbalances: a dictator dealing with an oppressed population, a master's dealings with a slave. We surely need to be able to criticise these as unjust.

However, in such scenarios we can imagine that the situation can in principle become procedurally just; that relationships between the powerful and powerless might (after campaigns, protest, external intervention) alter, through liberation of the powerless. The slave might be freed, the torture victim may get their day in court, facing their tormentor. But there are cases in which these things are not imaginable. There is simply no way in which non-human animals can even in principle negotiate with humans to alter their conditions of power inequality. And people a 100 years hence have absolutely no way of seeking justice vis-à-vis things that we have done to them. Such basic conditions cannot change and become "structurally just". Those who are wholly within our power, it seems, do not comfortably fit the metaphor of procedural justice.

Conditions here do not - and cannot ever - constitute conditions of fairness. And our primary concern here is the presumption that what is required is, in the first place, moral reasoning from impartiality, rather than from care. Part of the proceduralist intuition here seems to be provide reasons for non-moral actors (e.g. self-interested actors in positions of power) to be motivated to take on board the interests of others as valid. But here there is always the risk of "bad faith"; that in moving from the assumption of self-interest to transposing that to real or imagined conditions of fairness or neutrality (whether through mutual advantage, reciprocity or devices such as the original position), self-interest can trump $^{92}$ (e.g. through free-riding). Why not recognise that our underlying motivation for wanting to take the interests of the disempowered into account in the first place is because we care about them? Why try to

92. Groves (2014) helpfully terms this a form of "moral corruption", "in which the temptation is to privilege the short-term interests of present people over any potentially longer-term obligations" (p. 22). 
be impartial? Why not instead be more honest about our moral motivations, and reason (and encourage reasoning) directly from care rather than from a mitigatory ethic that relies on (at least the hypothetical presumption of) mutual self-interest?

And this will, therefore, also often be true in the case of relationships between contemporaries. While it may be possible to make a case in some scenarios amongst contemporaries that the conditions of procedural justice can (unlike for future generations) be created and (as we suggested in the Section II.ii) some conception of fairness meaningfully be appealed to, even here, what is often (and should) surely be motivating even these concerns (if indeed they are genuine concerns rather than a cynical move to protect one's own interests in the longer term ${ }^{93}$ ) is a care for those others who might potentially have been unjustly treated. ${ }^{94}$ And such motivations as underpinning and justifying this procedural justice must, surely, be emphasised and encouraged if such a system is to be lasting and stable; otherwise the cynical position will always give rise to occasions of free-riding and defection from cooperation with just procedures if self-interest is particularly strong. But there are also some cases of relationships between contemporaries where, as with relationships between (non-overlapping) generations, we can make no sense in principle of how the relationship might be "improved" so as to become procedurally just.

Take what may be a more intuitive example from existing experience. Treating one's baby merely "fairly" would be (considered - rightly) abominable. Yes, babies will one day grow up to be our equals (unless and this is crucial, of course - we prevent them from growing up to do so) and yes, technically, babies are already in some sense our competitors for certain resources; parents to an extent must balance their own needs against those of their baby. But to think of them primarily via this metaphor fails to understand the dynamic of the parent-child relationship, where the needs of the child redirect and reorder the wants and priorities of the parent, on whom the (young) child is utterly dependent. ${ }^{95}$ Parents act appropriately when they do what they can to care for their child, and are fundamentally motivated by love for them. Their relative position of power does not trigger duties of fairness. Dividing food or warmth or shelter or whatever it might be "fairly," in such a circumstance would make one question the ability of the parent to appropri-

93. Because, say, one thinks that the application of these rules will benefit oneself in the future.

94. We are here alluding to care ethics (as developed in the work of, for example, Carol Gilligan, Sarah Ruddick and Michael Slote).

95. This is not to advocate a self-sacrificing model of parenthood, which has historically been used to oppress women, subsuming their identities in their role as mother. 
ately care for the child. Such "fairness" is a standing invitation to bad faith; because there can be no "contract" here, no agreement, no negotiation: just whatever you decide "is" fair. But it is hardly fair for fairness to be a matter of the utterly powerful dictating to the utterly powerless. It is the rankest idealism to pretend otherwise: to pretend that one is likely to be fair, when one controls the very conditions of existence of the other, and is motivated only by cool fairness (and not by a prior "warmer" 96 motivation for why one should be fair). That is to say that if one starts (as Rawls, within the original position at least, and other contractualists do, with their assumption of mutual disinterest) by assuming we are only interested in ourselves, and then try to "balance" this "fairly" against others" "self-interest", then a tacit invitation to bad faith is present. There is nothing to keep one's alleged rationality on the rails. ${ }^{97}$ It is better to genuinely care about the other and proactively act in their interests... Only then can you be truly "fair" to future generations: genuine fairness has to be motivated by an ethic of care. Once more then, justice is not a primary virtue (and in that sense certainly not the "first" virtue); we are just, if we are, ultimately, because we care. This cannot be derived from arbitrating between different self-interests. There is something more basic than (justice as) fairness, without which fairness does not even get going. . and that something is something like: care.

Another analogy may help things here. Solow had referred earlier (see Section II.iii) to a theoretical "fair minded judge". But this is reminiscent of the biblical story of the judgement of Solomon, which offers a useful metaphor. In the story, two women both claim to be the mother of a baby and ask King Solomon to adjudicate. Solomon then feigns a threatened "fair" solution to determine the baby's true mother, ordering: "Cut the living child in two and give half to one and half to the other". While the false mother agrees with the ruling as a fair solution, the true mother "was deeply moved out of love for her son and said to the king, "Please, my lord, give her the living baby! Don't kill him!" But the other said, "Neither I nor you shall have him. Cut him in two!". ${ }^{98}$ Thus, the king recognises the true mother for her concern for the welfare of the baby - her recognition that its worth and value

96. For some explication of the quite-reasonable deep-seatedness of the connection between justice and coldness and between care and warmth, see http://chelseagreen.com/ blogs/georgelakoff/2010/02/22/george-lakoff-why-rational-reason-doesnt-work-in-contemporary-politics/ and http://blogs.scientificamerican.com/guest-blog/2011/11/04/abrief-guide-to-embodied-cognition-why-you-are-not-your-brain/. For the full background, see Lakoff's work, including his co-authored books with Nunez and of course with Johnson.

97. Such cases of failures of fairness based on alleged rationality alone are legion. Arguably, they include most extant climate treaties, for instance.

98. 1, Kings 3:24-27, New International Version. 
lies in its continued health, and that it is not the kind of thing that can be divided fairly and impartially. We think much the same of the health of our descendants. Specifically: Using the criterion of fairness to balance between us and them is liable to be equivalent to sawing them in two. However, the wisdom of real care involves a vital generosity of spirit.

Thus, the importance of a care-based metaphor will hold even for some contemporary relations. It should constitute an important supplementary metaphor to that of procedural justice, we would suggest, even in the cases we noted earlier, such as relationships between oppressors and the oppressed. What is missing in these cases is mutual care, and it is this that must underlie any genuine structural conditions of equity that might eventually pertain once the oppressive institutions have been overcome. But, it is even more important in the case of those contemporary relationships where there are two utter unequals, between whom there can be no fairness, no genuine equity. The metaphor needs to be central in the case of long-term intergenerational relationships (and those between humans and non-humans) where (unlike in the case of parents and children) the power dynamic cannot even shift over time.

In this sense, what Page called the "problem of non-reciprocity" is only a problem for those that think primarily in terms of procedural justice; non-reciprocity is not problematic when we think in terms of care. (Thus, the use of the term "problem" is revealing: It reveals the need for the "paradigm shift" that we are arguing for here) The shift in emphasis also reveals an additional concern with the Lockean Proviso, and Brundtland's (as well as other, general, forms of) sufficientarianism, a concern which compounds our earlier worry in Section II.iii about their attachment to the distributional metaphor. This is that such approaches are motivated by thinking about what we can get as limited by what we need to give/leave to "others" - a presumption in favour of the (narrowly construed interests of the) present, and of sustaining and maintaining current systems, which may not in fact protect the interests of future generations. We need, rather, to care for them.

We turn now to outline in more detail the kind of approach which we believe should be taken, to more centrally recognise the asymmetry that is characteristic of the various (otherwise "challenging"99 ) features of our intergenerational moral relationships and our obligations to improve ecological conditions for the well-being of future generations.

99. As characterised by e.g. Gosseries and Meyer (2009: 3). 
What we have in mind is that caring for the future is a way of "midwifing" the development of the future as emanating from - being "birthed"100 from - the present. And the underlying problem for conventional approaches to intergenerational relations, we suggest, is that Rawls's philosophy (as well as that of Solow, Page, Gosseries and of all these philosophers of intergenerational justice) is "ideal theory,"101 and yet the main bases for such "ideal theory" are quite clearly the concerns of the present. When Rawls et al. think of the future, it is primarily, as it were, as a quasi-spatial extension of the present. ${ }^{102}$ It is not just then that one is faced with a tension between ideal theory and non-ideal politics, which can seem to resolve into a tension between intergenerational justice and social justice, or even between intergenerational justice and present-day selfishness. The fundamental problem, as we see it, is that thinking through the prism of "intergenerational justice" or "intergenerational equity" is itself already "unjust" to future people, to the true nature of our concern for the flourishing and development of a future we can be proud of fostering. That is, It does not do them justice... Because to think in terms of intergenerational justice is still covertly to think in a present-centric way. Because justice-thinking is modelled, structured, both on thinking that works for distribution and via negotiation, between (some) people who are alive. If one is really to give future people their due, one needs to think in a different way. One needs to think time, not space. One needs to think beyond "distribution", beyond impartial negotiation, and thus beyond "fairness". 103

Our moral obligations to future generations should instead be seen, firstly, developmentally rather than distributionally. That is, developing (our) society in a way that protects and enhances its ecological pre-conditions to enable its continued functioning and flourishing, with any current "costs" considered in terms of how they alter its development, rather than straightforwardly as burdens that might be fairly or unfairly "dis-

100. Such terms may well appear odd and somewhat alien to the more analytical discourse of much of academic philosophy. But the change in ethos that we are advocating in political philosophy is partially constituted by (and can only be adequately communicated via) a shift in language - away from apparently impartial terminology to something more evocative.

101. See p.8f. of Rawls (1971).

102. Even if Rawls, as noted earlier (Section II.iii), is occasionally at pains to emphasise the unidirectionality of time (1971: 291), he is still, as we have suggested, wedded to metaphors that make this difficult to take seriously.

103. Bearing in mind of course here Rawls's famous formulation of "justice as fairness". 
tributed" intergenerationally. ${ }^{104}$ And this relies, secondly, not on reasoning impartially under "fair" conditions, but on reasoning in terms of care and love, roughly modelled on the relationships between parents and their children.

We now sketch these kinds of alternative metaphors that we think essential for an ecologically sane political philosophy, that is, to capture those necessary features of intergenerational moral relationships ignored by the (currently dominant) distributive and procedural justice metaphors. This is the major positive outcome of the present paper; it aims to open up a new research-agenda.

What we have suggested is mischaracterised by those (i.e. justicebased) approaches that are currently dominant but whose paradigm is in crisis, is, above all, a deep conceptual recognition of the asymmetry and directionality of our relationship with the future. That is, an understanding of future generations not as another distinct group of people(s) located elsewhere in time as opposed to space, but as "sequentially" and (ultimately) utterly asymmetrically dependent on us for the conditions in which they live. This dependency should be understood not simply (as under distributive justice) in terms of their being recipients of capital, but in the sense that they emerge from us and our world; the form of their societies, the health of their ecosystems and their very identities are at stake. This is in contrast to the distributive "saving" metaphor which implies a stockpile of goods, set aside and given to/saved up for future generations. Rather, over time our generation becomes them. ${ }^{105}$ Their planet is also ours, as it changes and (hopefully mostly) stays the same.

Under this approach, we need to consider our moral obligations to future generations and the prevention of harms in terms of investing in and shaping future conditions for flourishing - our responsibility for how our world will become - rather than considering future generations as competitors for intertemporal resources. Any gardener will be familiar with this way of thinking, exemplified through the rosemary bush anal-

\footnotetext{
104. This does not justify just any costs; there must be a genuine just transition, since we cannot (literally) immediately live within our ecological means without fundamentally threatening the existence of society, and in this sense, the "costs" of mitigation are spread across, for example, perhaps a generation.

105. In saying this, we have some sympathy with De Shalit's notion of a transgenerational community, as "one that extends into the future" (De Shalit, Avner (1995:12), Why Posterity Matters: Environmental policies and future generations, ed. Andrew Brennan, London and New York: Routledge). However, De Shalit oddly uses this to justify considering our obligations to near future generations in terms of intergenerational distributive justice (i.e. since they are a part of the transgenerational community, where conditions of justice apply), which is very different to our "developmental" approach. That is, De Shalit does not succeed in effecting a "paradigm shift"; he remains captured by distributive and spatial metaphors, even as he seeks to overcome their limitations.
} 
ogy described above. For the land to support life in the future requires time and money to be spent working the soil, enriching it with compost, manure etc., planting seeds (which means, if they are from a previous crop, not consuming them) so that they can grow productively in subsequent years. More will be harvested in the future than now but this is a defining feature of the (directional) process. And this means holding back from some "opportunities" now in the use of particular "resources" such as the greenhouse-gas absorption capacity to ensure that future lives are liveable, "even if" quality of life ends up being better subsequently than ours is now. ${ }^{106}$

For us to do this even when we ourselves will not directly benefit then involves moving beyond procedural justice contract metaphors of reasoning via impartiality between self-interested parties. It involves a "bias" towards the future; an attitude of love/care to future generations, as Jonas has suggested, analogously to our relationship with our children. ${ }^{107}$ Future generations (including the wider ecological community) are not our competitors because they are the development (the continuation into the future) of our communities.

Jonas argues in fact - and we agree - that the parent-child relation is an archetype of responsibility...:

When asked for a single instance (one is enough to break the ontological dogma) where the coincidence of the "is" and "ought" occurs, we can point at the most familiar sight: the newborn, whose mere breathing uncontradictably addresses an ought to the world around, namely, to take care of him. ${ }^{108}$

This is not even an "entreaty" because the infant cannot yet entreat us. Future people are quieter still - and thus even more in need of our "responsiveness". The only key point on which we differ from Jonas is on the centrality of the cultivation of a generosity of spirit, a spirit of care (or love):

Thus no mention [need be] made of sympathy, pity, or whichever of the emotions may come into play on our part, and not even love. ${ }^{109}$

106. At this point, as a reality-check, we should remark that of course on a business-asusual model our descendants (if they exist at all) will end up far worse off than we are. A desperately sad situation: one which requires us to give our all to avoid it, at the cost otherwise of emptying our own lives of worth, decency and meaning.

107. Jonas (1985: 39). Cf. also Groves's argument of his (2014:132-3).

108. Jonas (1985: 131).

109. Ibid. Interestingly for present purposes, given our criticisms of Rawls's contractualism above, Jonas goes on thus: "But precisely this in its wholly contingent uniqueness is that to which responsibility is now committed - the only case where the "cause" one serves has nothing to do with appraisal of worthiness, nothing with comparison, and nothing with contract." (134-5; emphasis ours) ... Not at all the "only case", we think, but surely (as Jonas says previously) a kind of an "archetype". 
In a certain sense, Jonas then goes even further than we do. He thinks that the fact of the world in itself simply gives us an absolute responsibility to take responsibility for those utterly dependent upon us. However, we advise the call of and the cultivation of care and the like (i.e. love). The facticity of the world and its creatures may give one what both Jonas and we want - but only if the right kind of attention is paid to it, to them, to us (all). Caring, or loving attention.

Thus, while Jonas calls for a new ethic of responsibility that he thinks emerges directly from the objects of that responsibility, we call for that ethic of responsibility to be an ethic of care, ${ }^{110}$ and insist that it requires the active involvement and "acknowledgement" of all of us. We need to develop the future out of ourselves, as carers do.

But it will be objected once again that it is one thing to love one's children, or even children in general, and quite another to love nameless, faceless future people. Especially given that we cannot know for certain that they will come to exist at all. Compare here the following useful remarks of Joel Feinberg's:

Unborn generations are more remotely potential than fetuses in one sense, but not in another. A much greater period of time with a far greater number of causally necessary and important events must pass before their potentiality can be actualized, it is true: but our collective posterity is just as certain to come into existence "in the normal course of events" as is any given fetus now in its mother's womb. In that sense the existence of the distant human future is no more remotely potential than that of a particular child already on its way. ${ }^{111}$

But, it might be said, over a generation since Feinberg wrote this, we now do worry whether in the normal course of events collective posterity is certain. Yet: if a parent knows that the life of their unborn child is under threat, this does not inevitably result in their becoming distanced from it, preparing to give it up. On the contrary, it might motivate the parents to care for it all the more intently, to protect it. Similarly: the fact that future generations are under threat is no reason for diminishing our degree of love and care for them. On the contrary, it gives us a motivation to care for them all the more intently. We can awaken to our latent care for the future, if we pay attention to its needs, its fragility. Its very

110. And here of course we are in part influenced by the epochal work, revisionary of the basis of justice-thinking, of Gilligan (See e.g. Gilligan (2011)). But we go beyond this, in finding Gilligan still too beholden to "justice".

111. Feinberg, J., "The rights of animals and unborn generations", in Partridge (1981). Feinberg, as one might put it, sees correctly the concrete potentiality of future people (as opposed to the merely abstract potentiality of hypothetical, imaginary beings conjured in thought experiments as possible bearers of justice, such as, say, GM-created centaurs). 
fragility, like that of a newborn, can awaken us to love for it. And that, at last, might be enough.

\section{Conclusion}

We acknowledge the attractions of the idea that justice-thinking should dominate ethical thinking about future generations. The notion of justice can seem to be especially appropriate hereabouts, since it can be understood impersonally. It can seem obvious that, with regard to future generations, there's none of the individual morality we have in the present: because future generations are amorphous. Because who exactly they are is not yet decided, and because we cannot in any case relate to them in their concrete particularity (yet). There is only future-generations-as-awhole; and our responsibilities towards them can (so it is said, or assumed) be understood fully by extending justice-thinking - and especially, distributive-justice-thinking - to cover them.

In the present paper, we have argued that this line of thinking fails to take account of the deep reasons why justice-thinking does not succeed in capturing what we owe to future generations, and indeed in crucial respects fares much worse with regard to thinking about the future than it does even with regard to thinking about the present (Unsurprisingly perhaps: since the present was what it was devised to deal with). We have argued that justice-thinking, while purportedly simply sensitive to the difficulties that there are in empathising with future people, actually magnifies - exacerbates - those difficulties, including through its very (proceduralist) "impartialism," which ends up being an open (though of course tacit) invitation to bad faith, not taking into account the entire dependence of the future upon the present. We have argued further that the crucial "distributive justice" frame in particular actually cannot bring into focus the most salient aspects of our comportment with regard to future generations. For future generations should not be thought of as a distinct society or group living at a different temporal "location," but as what/who we will become, emerging from our generation, and the future identity of our society(ies). And this has the implication that the frame of "justice" is much less appropriate for our relations to them than the frame of "care". As is the case with regard to infants. After all, the relative "unformedness" of our children at their birth does not reduce or occlude our level of care for them: on the very contrary.

Once we recall that future generations grow from and are formed by the structures and conditions of current generations, the dynamic is not simply a question of harms to "them" vs. harms to "us". Indeed, the 
very idea of separating "them" out from "us" starts to dissolve on one. Rather, the focus of decision-making that ethically recognises future generations should be on how we can effect a transition to enable us to live within our ecological limits and the boundaries of our global commons, to enable "them" to flourish. But this is not a question of what we should give and take, but of the society and wider ecological community we want to co-create and to be. It is, therefore, also the question of how we can become the future. How we can effect the transition from the present to the future demos.

What the future needs is not just justice, but, much more, care ethics. A care ethic, in fact, oriented specifically towards the future.

\section{References}

Anand, S. and A. Sen (2000). "Human Development and Economic Sustainability." World Development 28: 2029-2049.

Barry, B. (1991). "Justice as Reciprocity", Liberty and Justice: Essays in Political Theory 2. Oxford: Clarendon Press.

(1995). Justice as Impartiality. Oxford: Oxford University Press.

Beckerman, W. and J. Pasek (2001). Justice, Posterity and the Environment. Oxford: Oxford University Press.

Daly, H. and J. B. Jr Cobb (1990). For the Common Good: Redirecting the Economy Toward Community, the Environment, and a Sustainable Future. Boston: Green Print.

Feinberg, J. (1981). "The Rights of Animals and Unborn Generations." In E. Partridge (ed.), Responsibilities to Future Generations: Environmental Ethics. New York, NY: Prometheus, pp. 139-150.

Foster, J. (2008). The Sustainability Mirage: Illusion and Reality in the Coming War on Climate Change. Oxon: Earthscan.

Gardiner, S. M. (2004). "The Global Warming Tragedy and the Dangerous Illusion of the Kyoto Protocol." Ethics \& International Affairs 18: 23-39.

- (2009). "A Contract on Future Generations?”, in Gosseries and Meyer, Intergenerational Justice. Oxford: Oxford University Press.

Gilligan, C. (2011). Joining the Resistance. Cambridge: Polity.

Gosseries, A. (2008). "Theories of Intergenerational Justice: A Synopsis." SAPIENS 1. 1: 61-71.

Groves, C. (2014). Care, Uncertainty and Intergenerational Ethics. Basingstoke: Palgrave MacMillan.

Heidegger, M. (1977). The Question Concerning Technology and Other Essays. New York: Harper \& Row, trans. William Lovitt. 
Jonas, H. (1985). The Imperative of Responsibility: In Search of an Ethics for the Technological Age. Chicago: Univ. of Chicago Press.

Laslett, P. (1960). Locke: Two Treatises of Government. Cambridge: Cambridge University Press.

Meadows, D. H., J. Randers and D. L. Meadows (2005). Limits to Growth: The 30-Year Update. London: Earthscan.

Meyer, L. H. and D. Roser (2009). "Enough for the Future." In A. Gosseries and L. H. Meyer (eds.), Intergenerational Justice. Oxford: Oxford University Press, pp. 219-248.

Nussbaum, M. (2006). Frontiers of Justice. Cambridge, MA: Harvard University Press.

Page, E. (2006). Climate Change, Justice and Future Generations. Cheltenham: Edward Elgar Publishing.

(2007). "Fairness on the Day after Tomorrow: Justice, Reciprocity and Global Climate Change." Political Studies 55: 225-242.

Parfit, D. (1984). Reasons and Persons. Oxford: Clarendon Press.

Rawls, J. (1971). A Theory of Justice. Oxford: Oxford University Press.

Press.

Read, R. (2011). "Why the Ecological Crisis Spells the End of Liberalism: The 'Difference Principle' is Ecologically Unsustainable, Exploitative of Persons, orEmpty." Capitalism Nature Socialism 22: 80-94.

Scott Cato, M. (1999). "Distribution and Consumption of Resources." In M. Scott Cato and M. Kennett (eds.), Green Economics?: Beyond Supply and Demand to Meeting People's Needs. Aberystwyth, Wales: Green Audit Books.

Solow, R. M. (1974). "Intergenerational Equity and Exhaustible Resources." The Review of Economic Studies 41: 29-45.

Tremmel, J. C. (2009). A Theory of Intergenerational Justice. London: Earthscan.

Tuana, N., (2006). (Donald Brown, Nancy Tuana, Marilyn Averill, Paul Baer, Rubens Born, Carlos Eduardo Lessa Brandão, Robert Frodeman, Christiaan Hogenhuis, Thomas Heyd, John Lemons, Robert McKinstry, Mark Lutes, Benito Müller, José Domingos Gonzalez Miguez, Mohan Munasinghe, Maria Silvia Muylaert de Araujo, Carlos Nobre, Konrad Ott, Jouni Paavola, Christiano Pires de Campos, Luiz Pinguelli Rosa, Jon Rosales, Adam Rose, Edward Wells and Laura Westra), White Paper on the Ethical Dimensions of Climate Change. Pennsylvania State University, PA: Rock Ethics Institute. 